\title{
mTOR inhibitor RAD001 (everolimus) induces apoptotic, not autophagic cell death, in human nasopharyngeal carcinoma cells
}

\author{
YUCHEN CAI ${ }^{1,2^{*}}$, QING XIA ${ }^{1,3^{*}}$, QUANGUAN SU ${ }^{1,3}$, RONGZHEN LUO $^{1,3}$, \\ YUELI SUN $^{1,2}$, YANXIA SHI ${ }^{1,3}$ and WENQI JIANG ${ }^{1,3}$ \\ ${ }^{1}$ State Key Laboratory of Oncology in South China, Guangzhou, Guangdong; Departments of ${ }^{2}$ Experimental Research, \\ ${ }^{3}$ Medical Oncology, Sun Yat-sen University Cancer Center, Guangzhou, Guangdong, P.R. China
}

Received November 23, 2012; Accepted December 27, 2012

DOI: $10.3892 /$ ijmm.2013.1282

\begin{abstract}
Mammalian target of rapamycin (mTOR) is a serine/ threonine protein kinase and a key element in the phosphatidylinositol 3-kinase (PI3K)/protein kinase B (Akt) signaling pathway. Moreover, it is a negative regulator of autophagy and acts as a central regulator in cell growth. For the treatment of cancer, mTOR is a novel and validated therapeutic target. Previous studies have shown that Akt is frequently activated in nasopharyngeal carcinoma (NPC) tissues; thus, the inhibition of mTOR may be a treatment strategy for this tumor type. To evaluate the effect of the mTOR inhibitor RAD001 on NPC cell lines, we performed 4-[3-(4-iodophenyl)-2-(4-nitrophenyl)2H-5-tetrazolio]-1,3-benzene disulfonate (WST-1) assays, lactate dehydrogenase (LDH) assays, western blotting and flow cytometry to evaluate the mechanisms of cell death. The growth of both CNE-1 and HONE-1 cells was inhibited in a time- and dose-dependent manner. CNE-1 was more sensitive, with a $50 \%$ growth inhibition $\left(\mathrm{GI}_{50}\right)$ of $30.0 \pm 1.0 \mu \mathrm{M}$ compared to HONE-1, cells which had a GI ${ }_{50}$ of $56.9 \pm 13.1 \mu \mathrm{M}$. RAD001 induced apoptosis and autophagy in both cell lines. RAD001 induced a significant increase in growth inhibition in the two cell lines when used in combination with the autophagy inhibitor, 3-methyladenine; however, the percentages of apoptotic cells decreased when RAD001 was combined with the caspase inhibitor, z-VAD-fmk. In conclusion, the main
\end{abstract}

Correspondence to: Professor Wenqi Jiang or Professor Yanxia Shi, State Key Laboratory of Oncology in South China, Guangzhou, Guangdong 510275, P.R. China

E-mail: jiangwenqi2009@126.com

E-mail: shiyanxia2007@126.com

*Contributed equally

Abbreviations: NPC, nasopharyngeal carcinoma; mTOR, mammalian target of rapamycin; PARP, poly(ADP-ribose) polymerase; $\mathrm{GI}_{50}, 50 \%$ growth inhibition; PI, propidium iodide; WST-1, 4-[3-(4-iodophenyl)-2(4-nitrophenyl)-2H-5-tetrazolio]-1,3-benzene disulfonate; $\mathrm{LDH}$, lactate dehydrogenase

Key words: nasopharyngeal carcinoma, mTOR inhibitor, RAD001, apoptosis, autophagy mechanism of the mTOR inhibitor RAD001 in these two NPC cells was apoptotic, not autophagic cell death. The combination of RAD001 with autophagy inhibitors may be a useful therapeutic strategy for nasopharyngeal carcinoma.

\section{Introduction}

Nasopharyngeal carcinoma (NPC) is a significant health burden in Southeast Asia and Southern China. Radiotherapy is the primary treatment modality, and the use of radiation therapy in combination with chemotherapy is recommended for the treatment of locoregionally advanced tumors. However, in patients who develop distant recurrence following radiotherapy, the median survival time is $\sim 12-15$ months $(1,2)$; thus, new treatments are needed. Targeted therapy using specific inhibitors is currently in development and has demonstrated promising antitumor efficacy. The increasing knowledge of growth factor signal transduction pathways has led to speculation that proteins in these pathways could offer crucial targets for cancer therapy.

Cell death is the result of an unsuccessful cytoprotective mechanism against intracellular and extracellular stressors, which includes apoptosis, autophagy, necrosis and mitotic catastrophe. Autophagic cell death is morphologically characterized by a cell with an intact nucleus and an accumulation of cytoplasmic double-membrane autophagic vacuoles called autophagosomes. Apoptosis is characterized by chromatin condensation and DNA fragmentation. Anticancer drugs have been shown to induce not only apoptosis but also autophagy in cancer cells (3-5). However, the relationship between autophagy and apoptosis is complex as the molecular regulators of both pathways are interconnected. The crosstalk between autophagy and apoptosis can be in unison or in an opposing fashion, and it varies depending on cell type and the type and duration of the stimulus. Some published data suggest that tumor cell autophagy induced by anticancer therapy inhibits tumor cell killing. However, it has also been proposed that autophagy is a cell death mechanism that could function as a backup mode of cell death when apoptosis is disabled.

The mammalian target of rapamycin (mTOR), which is well-known as a major negative regulator of autophagy, is a serine/threonine protein kinase and is a key element of the phosphatidylinositol 3-kinase (PI3K)/protein kinase B (Akt) 
pathway that integrates signals that govern protein biosynthesis, cell division, motility, survival and angiogenesis (6). Therefore, mTOR acts as a central regulator of cell growth and cell cycle progression. The inhibition of mTOR prevents protein synthesis and cell proliferation. Recently, it has been suggested that dysregulation of mTOR contributes to oncogenesis in a broad range of cancers (7). Therefore, this protein is a novel and validated therapeutic target for the treatment of cancer (8-12).

RAD001 (everolimus) is the first oral mTOR inhibitor to reach oncology clinics (13). RAD001 inhibits mTOR complex 1 (mTORC1) and the phosphorylation of its downstream signaling mediators, ribosomal p70S6 kinase 1 (S6K) and 4E-binding protein 1 (4E-BP1). Treatment with RAD001 has been shown to induce autophagy in papillary thyroid cancer and enhance the therapeutic response to cytotoxic chemotherapy and external beam radiation (14). RAD001 inhibits growth in HPV-associated oral and cervical squamous carcinomas, ovarian cancer, post-transplant Epstein-Barr virus-related lymphoproliferative disorders, breast cancer and pancreatic neuroendocrine tumors (15-19), as well as diminishes lymphangiogenesis in primary tumors and prevents the dissemination of head and neck squamous cell cancer cells to the cervical lymph nodes (20). At present, RAD001 is currently undergoing evaluation studies in phases I-III as an antitumor agent.

Previous studies have shown that Akt is frequently activated in NPC tissues (21); therefore, the inhibition of mTOR may be an appropriate treatment strategy for this tumor type. In this study, we evaluated the activity of the mTOR inhibitor RAD001 on NPC cell lines and revealed that the inhibitory effect of RAD001 was mainly due to apoptosis rather than autophagy. Our data demonstrated that the combination of RAD001 and autophagy inhibitors may be a useful therapeutic strategy for nasopharyngeal carcinoma.

\section{Materials and methods}

Cell lines and small-molecule inhibitors. The human NPC cell lines HONE-1 and CNE-1 were grown in RPMI-1640 medium (Gibco, USA) supplemented with $10 \%$ fetal bovine serum (FBS) (Hyclone, Logan, UT, USA). All cells were cultured in a $5 \% \mathrm{CO}_{2}$ incubator at $37^{\circ} \mathrm{C}$. The working stock of RAD001 (Selleck Chemicals, USA) was diluted to $20 \mathrm{mM}$ using dimethyl sulfoxide (DMSO) and stored at $-20^{\circ} \mathrm{C}$. The concentration of DMSO in the final solution did not exceed $1 \%(\mathrm{v} / \mathrm{v})$. 3-Methyladenine (3-MA, \#M9281) from Sigma-Aldrich was dissolved in hot water $\left(70^{\circ} \mathrm{C}\right)$ to $30 \mathrm{mg} / \mathrm{ml}$ before use. Caspase inhibitor z-VAD-fmk (\#sc-3067, $0.5 \mathrm{mg} / 0.1 \mathrm{ml}$ ) was purchased from Santa Cruz Biotechnology, Inc., Santa Cruz, CA, USA).

\section{4-[3-(4-Iodophenyl)-2-(4-nitrophenyl)-2H-5-tetrazolio]-} 1,3-benzene disulfonate (WST-1) assay. The cells were dispensed in 96-well, flat-bottom microtiter plates at a density of $2 \times 10^{3}$ cells/well and incubated with RAD001 at various dilutions for 20,44 and $68 \mathrm{~h}$ followed by an additional $4 \mathrm{~h}$ treatment with WST-1 (Roche, Germany). The cleavage of WST-1 to formazan by metabolically active cells was quantified by scanning the plates in a microtiter plate reader at 440 and $620 \mathrm{~nm}$ (reference wavelength). The test medium was used as the background control. Three independent sets of experiments that were performed in triplicate were evaluated. The viability of the treated cells was normalized to the untreated control cells.

Cell shape assay. Twenty-four hours prior to drug treatment, the cells were seeded directly into 6 -well culture plates at a density of $1 \times 10^{5}$ cells/well. The cells were then treated with various concentrations of $\operatorname{RAD001}(0,20$ or $40 \mu \mathrm{M})$ for $24 \mathrm{~h}$, stained with DAPI, mounted, and analyzed using an inverted microscope (IX71; Olympus).

Cytotoxicity assay. The cytotoxicity assay was performed using the Cytotoxicity Detection Kit ${ }^{\text {PLUS }}$ LDH (\#04744926001; Roche) according to the manufacturer's instructions. This assay is based on the measurement of lactate dehydrogenase (LDH) activity released from the cytosol of damaged cell. Three controls are included: background control (assay medium), low control (untreated cells) and high control (maximum LDH release). To determine the experimental absorbance values, the average absorbance values of the triplicate samples and controls were calculated and subtracted from the absorbance values of the background control. The percent cytotoxicity was determined using the following equation: Cytotoxicity $(\%)=$ (exp. value - low control)/(high control - low control) x 100.

Analysis of cell apoptosis. Cells $\left(1 \times 10^{5}\right.$ cells $\left./ \mathrm{ml}\right)$ seeded in a 6-well plate were treated with RAD001 for $24 \mathrm{~h}$. For analysis of apoptosis, staining was performed using the Annexin V-FITC/PI Apoptosis Detection kit (\#PF032; Merck) according to the manufacturer's instructions. Both cell cycle distribution and apoptosis were analyzed using flow cytometry (FC500; Beckman Coulter, Brea, CA, USA), and the results were displayed as histograms.

Western blot analysis. Lysates were prepared from $4 \times 10^{5}$ cells by dissolving the cell pellets in $100 \mu \mathrm{l}$ of cell lysis buffer (\#9803; Cell Signaling Technology) for $30 \mathrm{~min}$ on ice. The lysates were centrifuged at $12,000 \mathrm{x} \mathrm{g}$ for $20 \mathrm{~min}$ and the supernatant was collected. The protein content was determined using the Pierce BCA Protein Assay (\#23225; Thermo Scientific). A total of $30 \mu \mathrm{g}$ of protein was loaded into each well of an 8-15\% SDS-PAGE gel. The resolved proteins were electrophoretically transferred to PVDF membranes and incubated sequentially with primary and secondary antibodies [anti-rabbit IgG, HRP-linked antibody (\#7074P2) or anti-mouse IgG, HRP-linked antibody (\#7076P2; both from Cell Signaling Technology)]. After washing, the bound antibody complex was detected using LumiGLO reagent (\#7003; Cell Signaling Technology) and XAR film (XBT-1; Kodak) as described by the manufacturers. The following primary antibodies were used: caspase-3 antibody (\#9662; Cell Signaling Technology); poly(ADP-ribose) polymerase (PARP) antibody (sc-7150; Santa Cruz Biotechnology, Inc.); LC3 antibody (NB100-2220; Novus Biologicals); and glyceraldehyde 3-phosphate dehydrogenase antibody (\#32233; Santa Cruz Biotechnology, Inc.).

Statistical analyses. All experiments were repeated three times. The results of multiple experiments are presented as the mean \pm SD. Statistical analyses were performed using the 
A

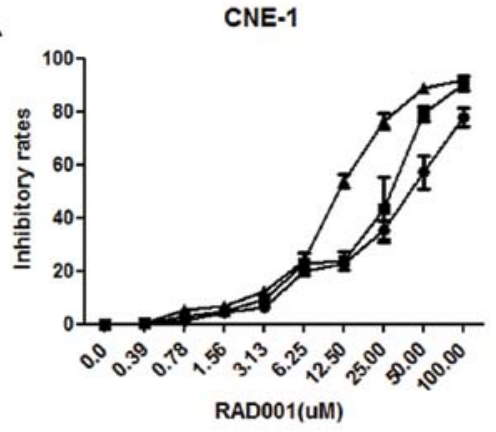

B
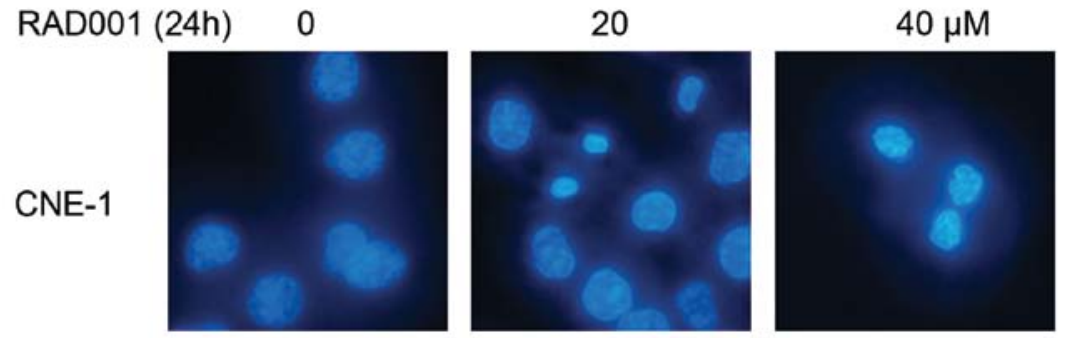

HONE-1
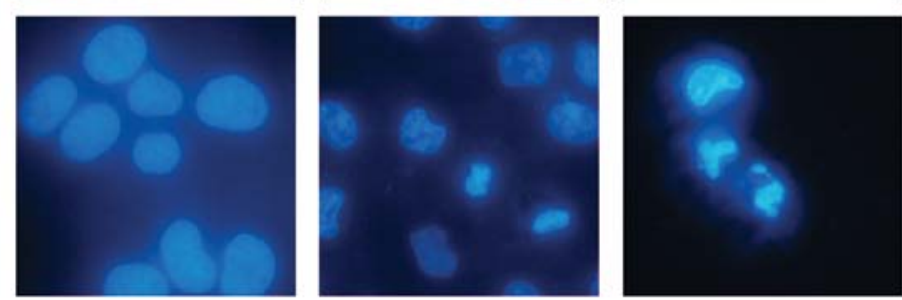

Figure 1. Antiproliferative and cell morphological effects of RAD001 on nasopharyngeal carcinoma (NPC) cells. (A) CNE-1 and HONE-1 cells were exposed to RAD001 for 24, 48 and $72 \mathrm{~h}$. The WST-1 assay was used to detect cell viability. Data points represent the means \pm SDs from triplicate experiments. (B) Effect of RAD001 on the cell morphology of NPC cells. CNE-1 and HONE-1 cells were treated with RAD001 for $24 \mathrm{~h}$, stained with DAPI and photographed under an inverted microscope. Original magnification, $\mathrm{x} 400$

Table I. Antiproliferative activities of RAD001 in human nasopharyngeal carcinoma cell lines.

\begin{tabular}{lll}
\hline & \multicolumn{2}{c}{$\mathrm{GI}_{50}(\mu \mathrm{M})$} \\
\cline { 2 - 3 } Time $(\mathrm{h})$ & $\mathrm{CNE}-1$ & HONE-1 \\
\hline 24 & $51.7 \pm 3.5$ & $96.6 \pm 2.0$ \\
48 & $40.3 \pm 2.9$ & $59.1 \pm 3.8$ \\
72 & $30.0 \pm 1.0$ & $56.9 \pm 13.1$ \\
\hline
\end{tabular}

SPSS 17.0 statistical software. The P-values were calculated using a one-way analysis of variance (ANOVA). A P-value of $<0.05$ was considered to indicate a statistically significant result.

\section{Results}

RAD001 inhibits the proliferation of NPC cells. We first examined the viability of the two NPC cell lines in the presence of different concentrations of RAD001 (0-100 $\mu \mathrm{M})$ using the WST-1 assay. CNE-1 cells were more sensitive, with a $50 \%$ growth inhibition $\left(\mathrm{GI}_{50}\right)$ of $30.0 \pm 1.0 \mu \mathrm{M}$ at $72 \mathrm{~h}$ compared to the $\mathrm{GI}_{50}$ of HONE-1, which was $56.9 \pm 13.1 \mu \mathrm{M}$ (Fig. 1A and Table I).
Cell morphological change. To examine the lethal effect of RAD001 in CNE-1 and HONE-1 cells, both cell lines were treated with different concentrations of RAD001 (0, 20 and $40 \mu \mathrm{M})$ for $24 \mathrm{~h}$. Cellular apoptosis was determined using DAPI staining. Chromatin condensation and cell shrinkage were clearly observed after RAD001 treatment (Fig. 1B).

RAD001 induces cellular apoptosis. To identify whether mTOR inhibition induces apoptosis, the treated cells were stained with Annexin V-FITC/PI and the apoptotic cell population was analyzed using flow cytometry. RAD001 treatment significantly increased the proportion of apoptotic cells (Fig. 2). In the control group, $3.1 \pm 1.1 \%$ cells were positive for Annexin V-FITC staining, and the 20,40 and $80 \mu \mathrm{M}$ RAD001 treatments resulted

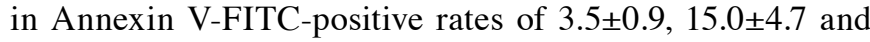
$27.0 \pm 15.3 \%$, respectively, in the CNE-1 cells treated for $24 \mathrm{~h}$. At $48 \mathrm{~h}$ post-treatment, the apoptotic rates increased to $3.8 \pm 0.8 \%$ for the control and to $9.5 \pm 6.3,52.3 \pm 11.8$ and $96.5 \pm 2.2 \%$, respectively, for the above-mentioned treatment groups. Similar results were observed in HONE-1 cells (Fig. 2 and Table II).

To demonstrate whether RAD001 treatment results in increased activation of caspases, we analyzed both the cleavage of PARP-1, a substrate cleaved by caspases during apoptosis, and the activated cleavage of caspase-3. Our western blotting results determined that procaspase- 3 was cleaved to yield a $17 \mathrm{kDa}$ fragment and PARP-1 was cleaved to an $89 \mathrm{kDa}$ fragment following treatment in both cell lines (Fig. 3). These results 
Table II. Effect of RAD001 on the apoptosis of CNE-1 and HONE-1 cells.

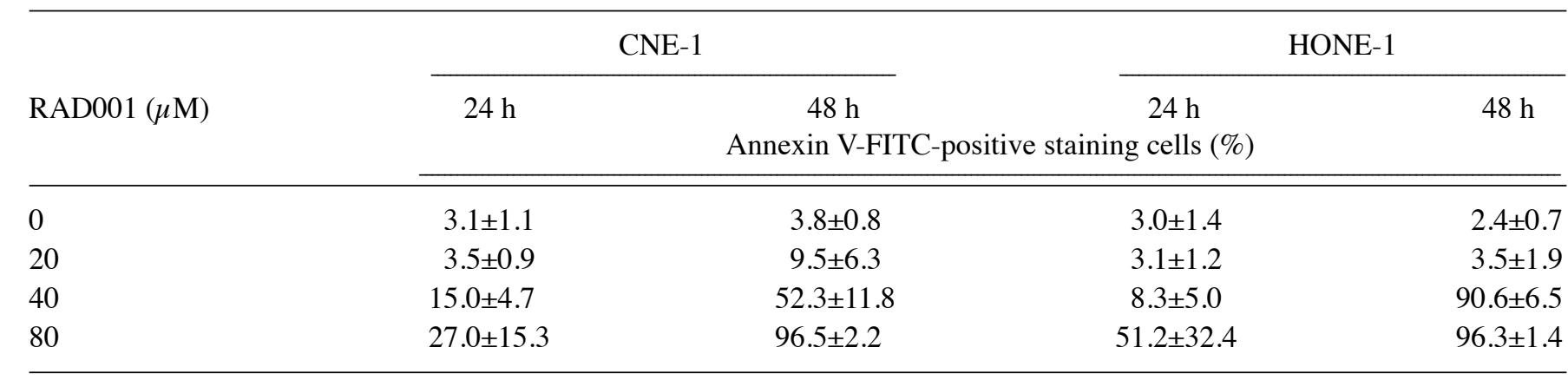

Data represent the means \pm SDs from triplicate experiments.

CNE-1
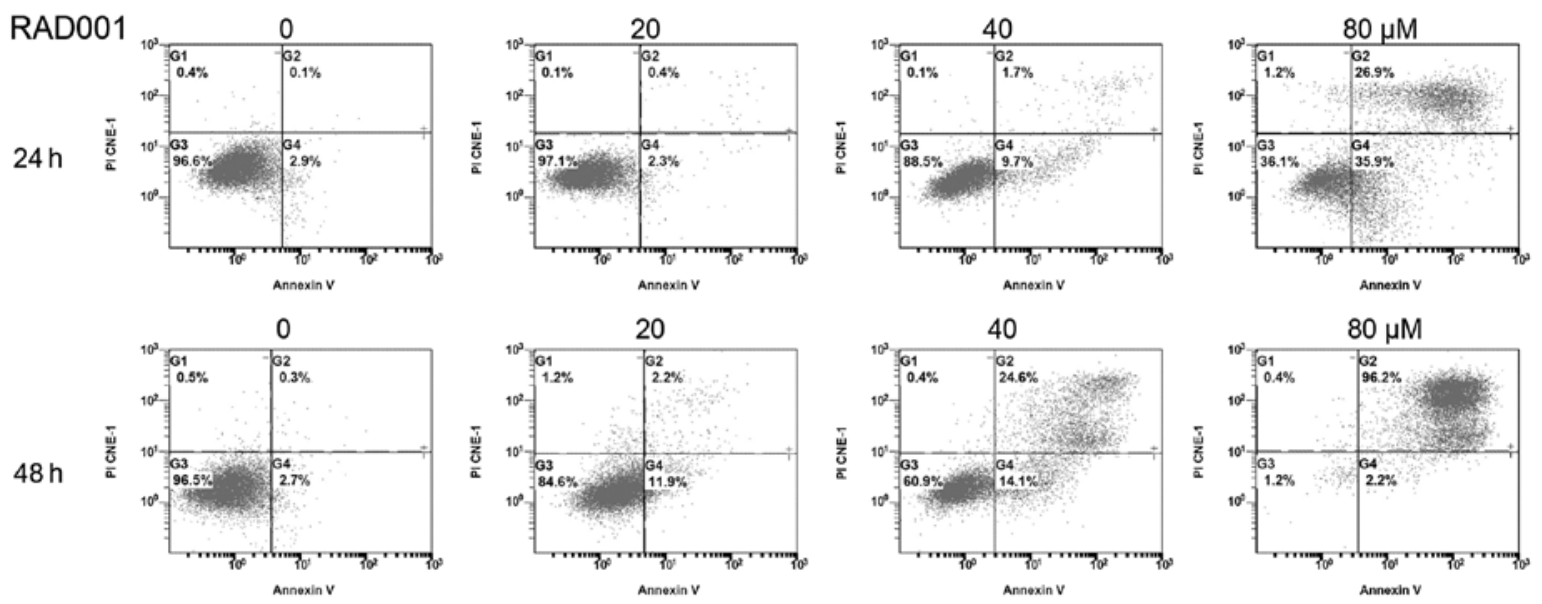

HONE-1

RAD001
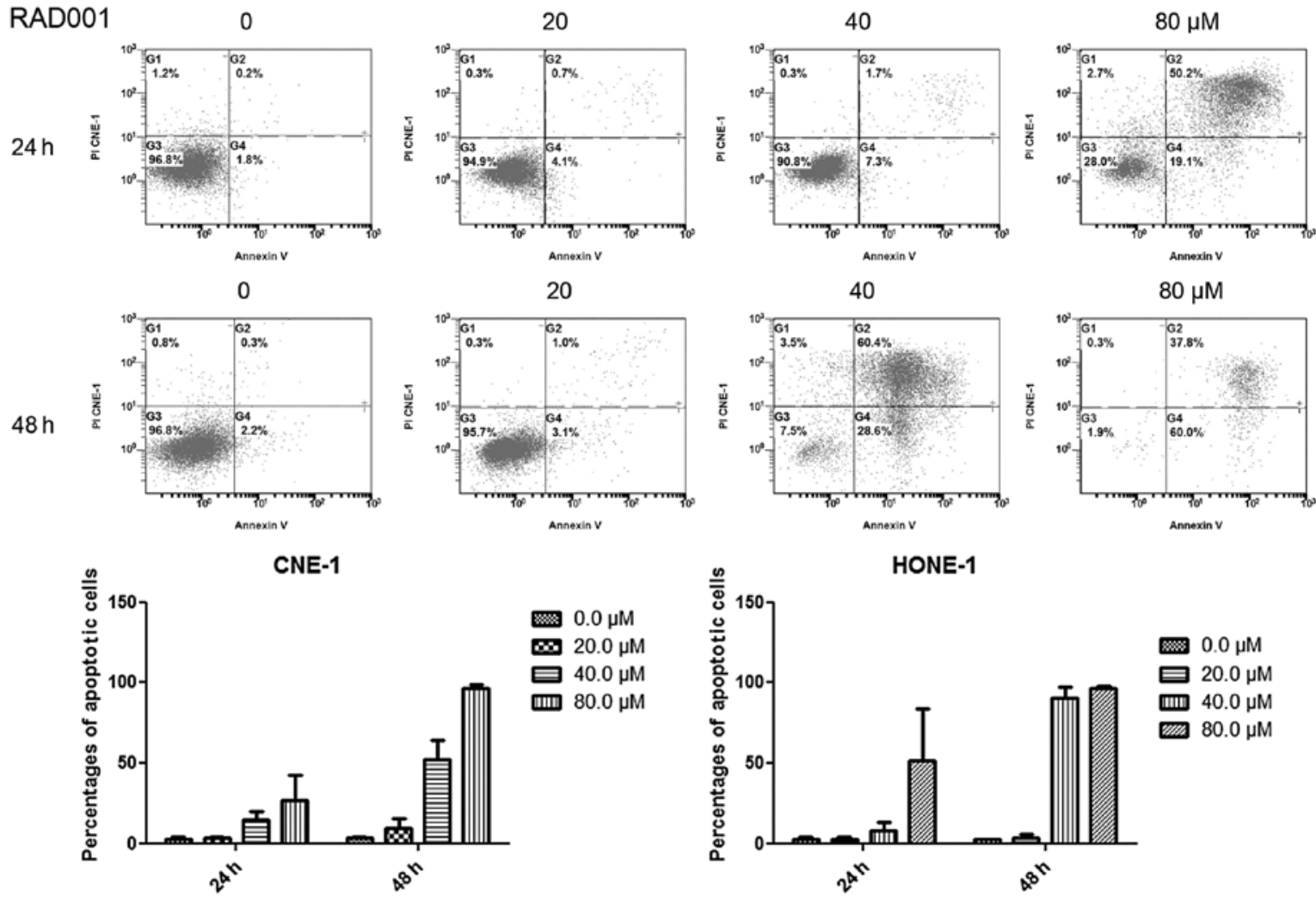

Figure 2. Effect of RAD001 on the apoptosis in CNE-1 and HONE-1 cells. Cells were treated with 0, 20, 40 and $80 \mu \mathrm{M}$ RAD001 for 24 and $48 \mathrm{~h}$ and then stained using the Annexin V-FITC/PI apoptosis detection kit. Data points represent the means \pm SDs from triplicate experiments. 
A

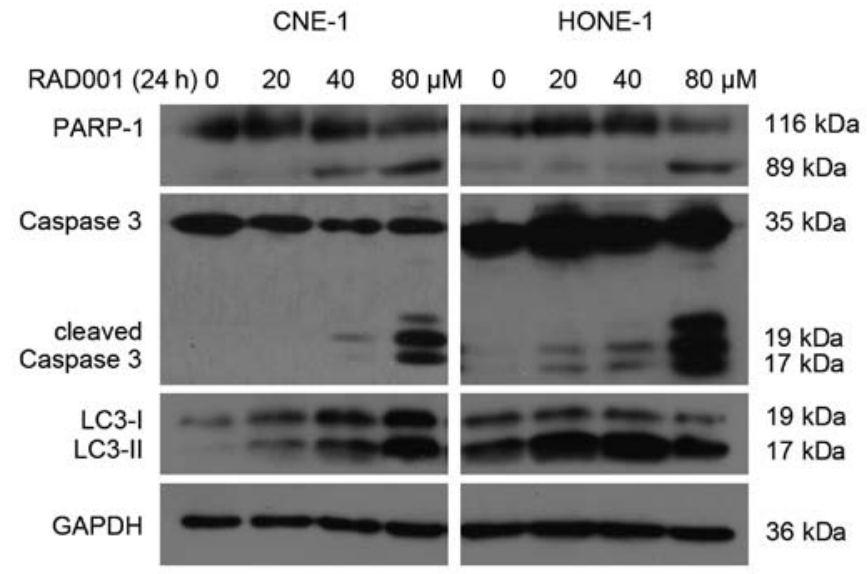

B

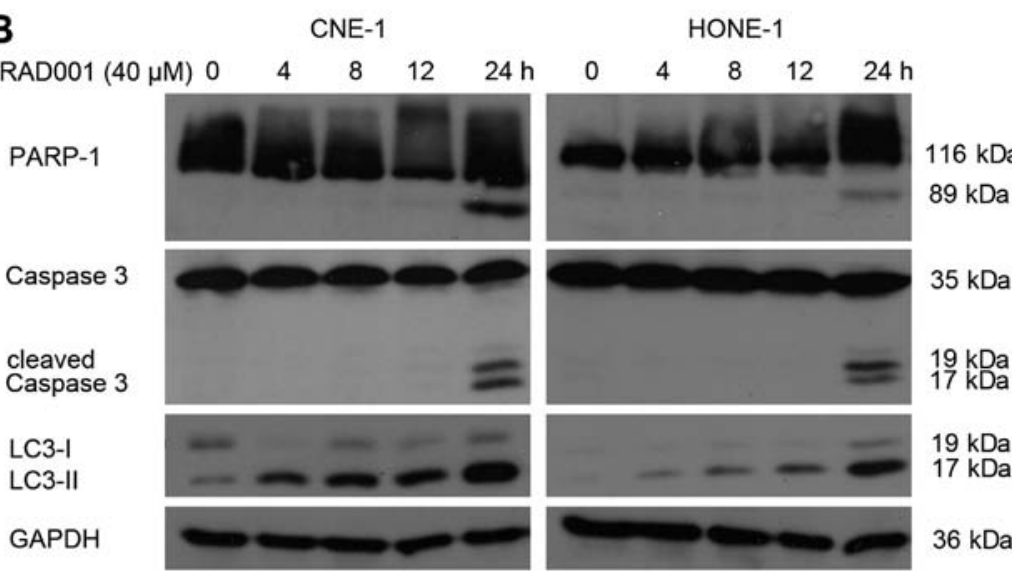

Figure 3. Effect of RAD001 on PARP-1 cleavage, caspase-3 cleavage and the LC3 expression level in CNE-1 and HONE-1 cells. Western blot analysis was performed on proteins extracted from cells treated (A) with RAD001 at 0,20,40 and $80 \mu \mathrm{M}$ for $24 \mathrm{~h}$ and (B) with RAD001 at $40 \mu \mathrm{M}$ at $0,4,8,12$ and $24 \mathrm{~h}$.

further confirmed that RAD001 induced caspase-3-dependent cell death in these two nasopharyngeal carcinoma cell lines. RAD001-treated NPC cells displayed typical signs of apoptotic cell death including chromatin condensation, cell shrinkage, cleavage of PARP and activation of caspase-3.

RAD001 induces cellular autophagy. mTOR is well known as a major negative regulator of autophagy and acts as a central regulator of the PI3K/Akt pathway, which can induce autophagy when inhibited. The membrane-associated light chain 3 protein (LC3, Atg8) is a key marker of autophagy. After the induction of autophagy, LC3-I is converted to LC3-II, which is most likely conjugated to phosphatidylethanolamine (PE) and tightly bound to the autophagosomal membranes, forming ring-shaped structures in the cytoplasm. The amount of PE-conjugated LC3 (LC3-II) correlates well with the number of autophagosomes. Therefore, we examined LC3-I/II expression using western blotting. RAD001 treatment caused the levels of LC3-II to increase in a dose- and time-dependent manner in both cell lines (Fig. 3).

Inhibition of autophagy enhances RAD001-induced cell growth inhibition and apoptosis. Since RAD001 induced both apoptosis and autophagy in CNE-1 and HONE-1 cells, we aimed to identify which mechanism of cell death was dominant. We first inhibited autophagy by combining RAD001 with the autophagy inhibitor, 3-MA. 3-MA is used to inhibit and study the mechanism of autophagy (lysosomal self-degradation). It inhibits autophagy by blocking autophagosome formation via the inhibition of type III PI3K. RAD001 of 40 and $80 \mu \mathrm{M}$ resulted in decreased survival rates of $34.9 \pm 2.4$ and $19.9 \pm 0.9 \%$ compared with the control group (100.0\%) in the CNE-1 cells (Fig. 4A). Furthermore, there was extensive growth inhibition in the combined treatment group. A survival rate of $17.3 \pm 0.5 \%$ $(\mathrm{P}<0.05)$ and $3.9 \pm 0.2 \%(\mathrm{P}<0.05)$ was noted when 40 and $80 \mu \mathrm{M}$ RAD001 was combined with $10 \mathrm{mM} 3-\mathrm{MA}$ in CNE-1 cells. Similar results were observed in the HONE-1 cells (Fig. 4A).

We next examined whether the combination was effective at inducing cellular apoptosis. As displayed in Fig. 4B, 3.4 $\pm 1.3 \%$ of the cells were positive for Annexin V-FITC staining in the CNE-1 cell control group. Treatment with 40 or $80 \mu \mathrm{M}$ RAD001 resulted in Annexin V-FITC-positive staining rates of $6.0 \pm 0.7$ and $15.2 \pm 3.6 \%$ at $24 \mathrm{~h}$. When 40 or $80 \mu \mathrm{M}$ RAD001 was combined with 3-MA, the Annexin V-FITC-positive staining rates were $9.0 \pm 1.8 \%(\mathrm{P}<0.05)$ and $34.5 \pm 4.7 \%(\mathrm{P}<0.01)$, respectively. The combination treatment significantly increased the proportion of apoptotic cells compared to this proportion following RAD001 treatment $(80 \mu \mathrm{M})$ alone $(\mathrm{P}=0.0024)$. Regarding the HONE-1 cells, RAD001 of 40 or $80 \mu \mathrm{M}$ resulted in the Annexin V-FITC-positive staining rates of 4.6 \pm 2.0 and $28.6 \pm 3.8 \%$ compared with the control group $(2.7 \pm 0.8 \%)$ at $24 \mathrm{~h}$. When 40 or $80 \mu \mathrm{M}$ RAD001 was combined with $10 \mathrm{mM} 3-\mathrm{MA}$, 
A

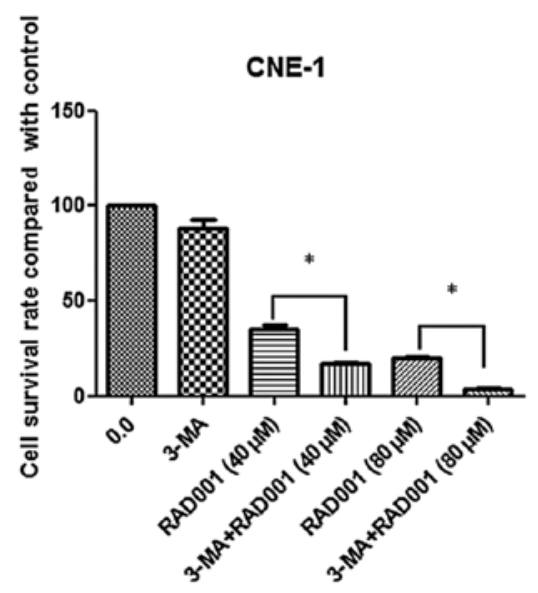

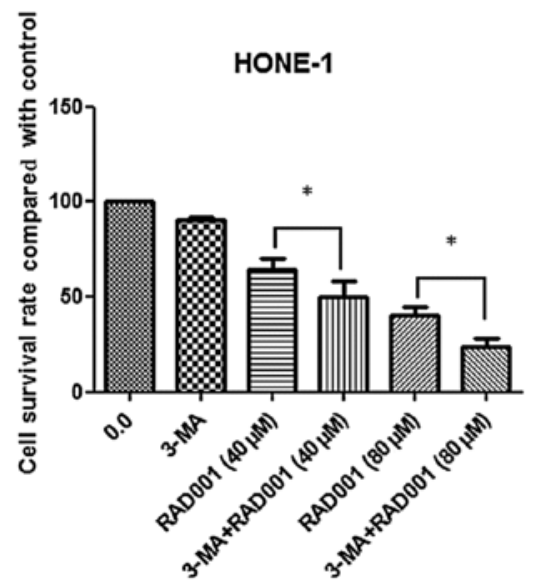

B

CNE-1

RAD001 (24 h)
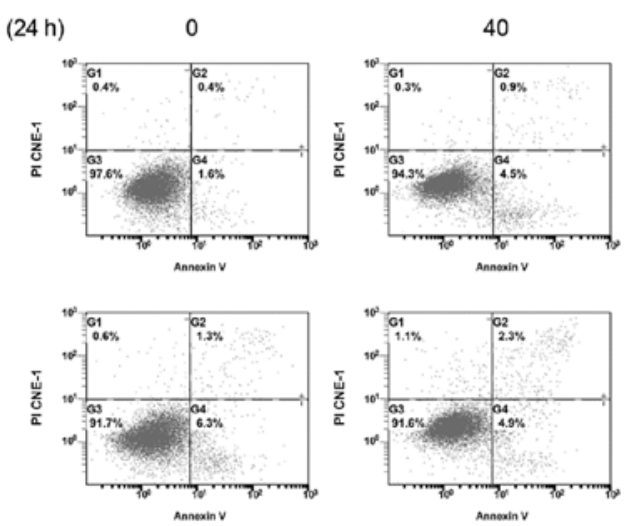

HONE-1

RAD001 (24 h)
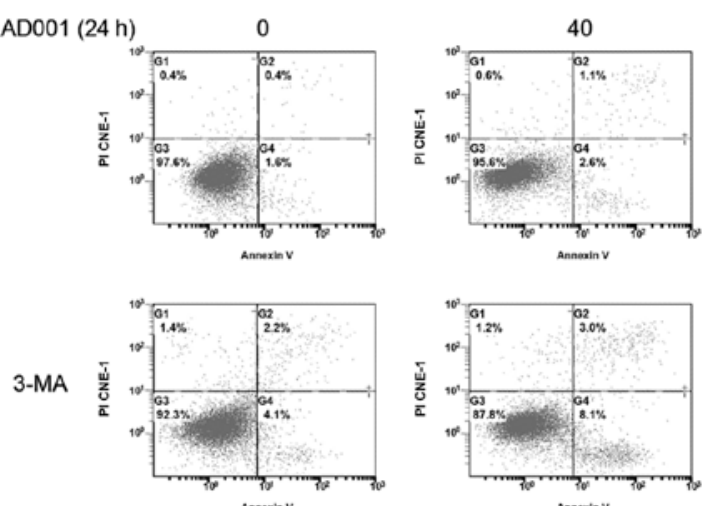
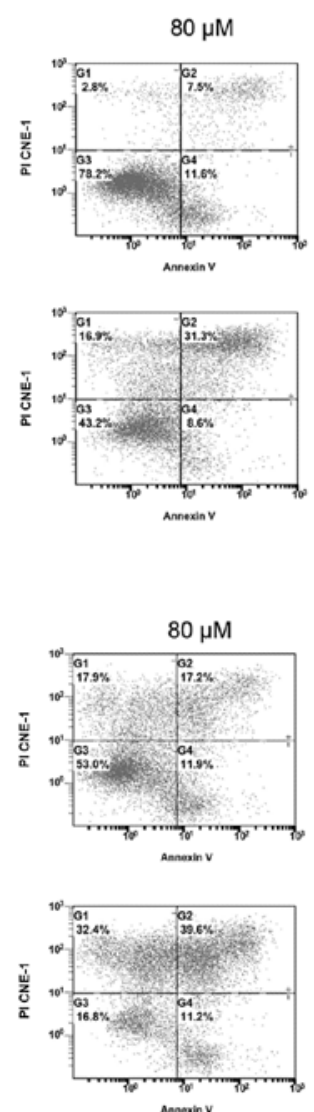
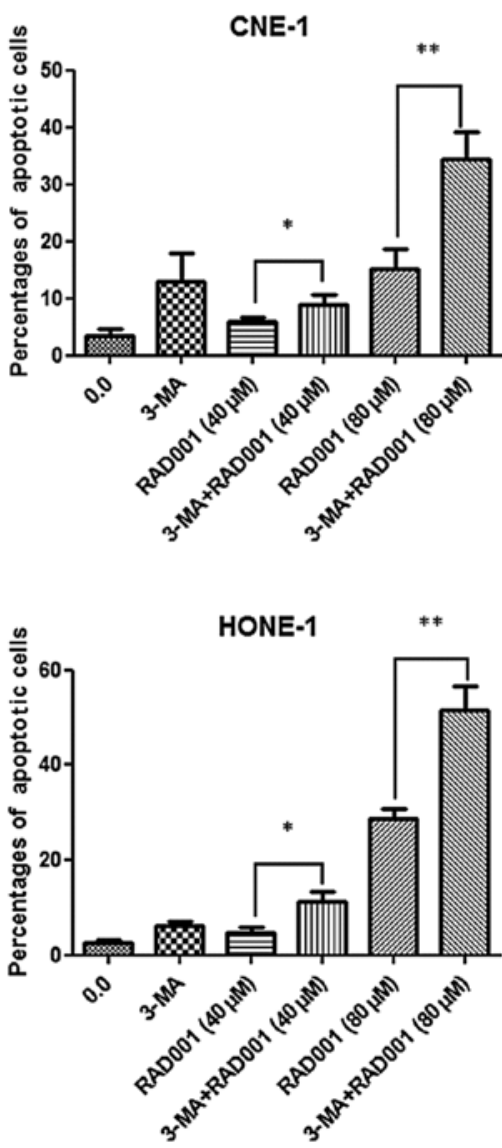

Figure 4. Effect of the combined RAD001 and 3-MA treatment on growth and apoptosis in CNE-1 and HONE-1 cells. (A) Cells were exposed to RAD001 alone or in combination with 3-MA for $24 \mathrm{~h}$. The WST-1 assay was used to detect cell viability. (B) Cells were exposed to RAD001 alone or in combination with 3-MA for $24 \mathrm{~h}$ and then were stained using an Annexin V-FITC/PI apoptosis detection kit. Data points represent the means \pm SDs from triplicate experiments $\left({ }^{*} \mathrm{P}<0.05,{ }^{* *} \mathrm{P}<0.01\right)$.

the Annexin V-FITC-positive staining rates were $11.4 \pm 3.7 \%$ $(\mathrm{P}<0.05)$ and $51.5 \pm 9.0 \%(\mathrm{P}=0.0076)$, respectively (Fig. 4B).

Inhibition of apoptosis decreases RAD001-induced cell death . We next combined RAD001 with the caspase-3 inhibitor z-VAD-fmk to determine whether inhibition of apoptosis decreases RAD001-induced cell death. Using an LDH assay we determined that the growth inhibition effect was markedly reduced in both CNE-1 and HONE-1 cells. As shown in Fig. 5A, 40 and $80 \mu \mathrm{M}$ RAD001 resulted in increased cytotox- icity rates of $37.1 \pm 4.3$ and $51.8 \pm 1.7 \%$ compared with the control group $(0.0 \%)$ in CNE-1 cells. When 40 or $80 \mu \mathrm{M}$ RAD001 was combined with $20 \mu \mathrm{M}$ z-VAD-fmk, the cytotoxicity rates were decreased to $12.5 \pm 5.9 \%(\mathrm{P}<0.01)$ and $23.8 \pm 1.7 \%(\mathrm{P}<0.01)$, respectively. Similar results were observed in HONE-1 cells (Fig. 5A).

Furthermore, using flow cytometry we examined whether the combination of RAD001 and z-VAD-fmk was effective at reducing cellular apoptosis. As shown in Fig. $5 \mathrm{~B}, 1.2 \pm 1.3 \%$ of the cells were positive for Annexin V-FITC staining in the CNE-1 
A

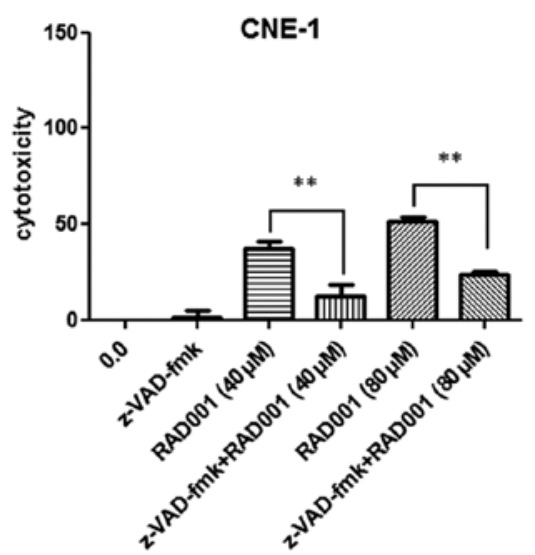

B

CNE-1
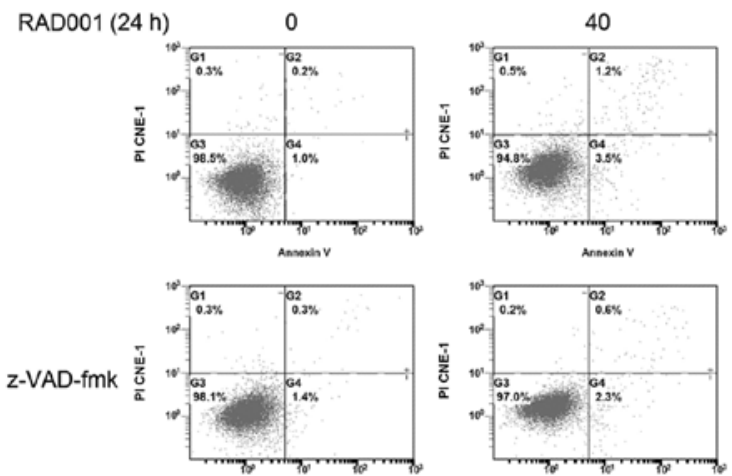

HONE-1

RAD001 (24h)
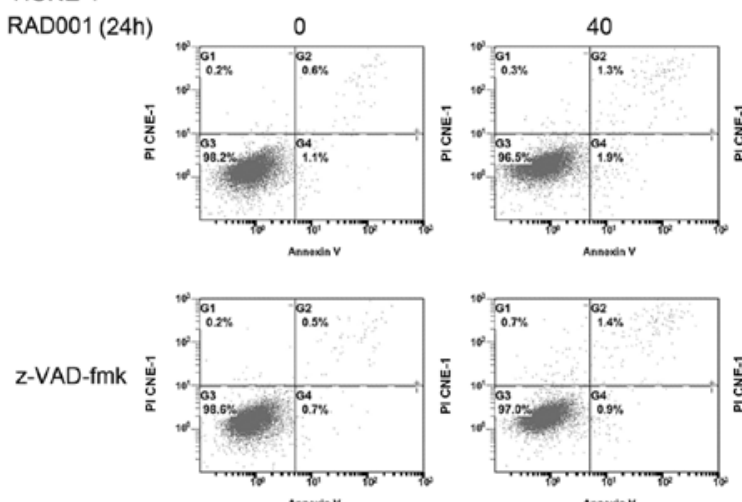
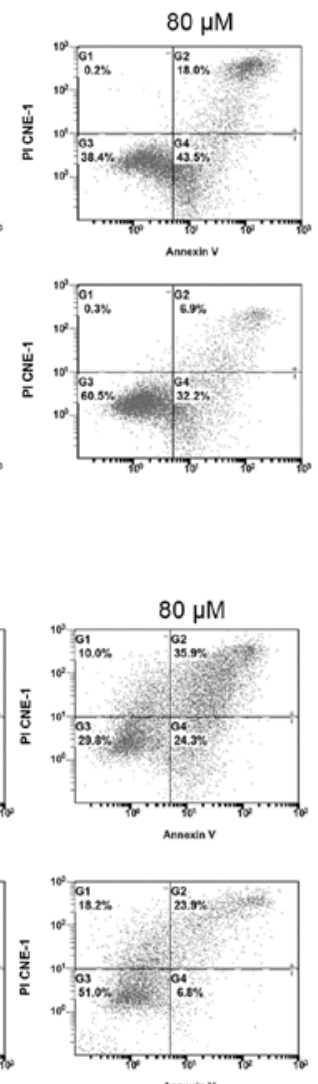

HONE-1
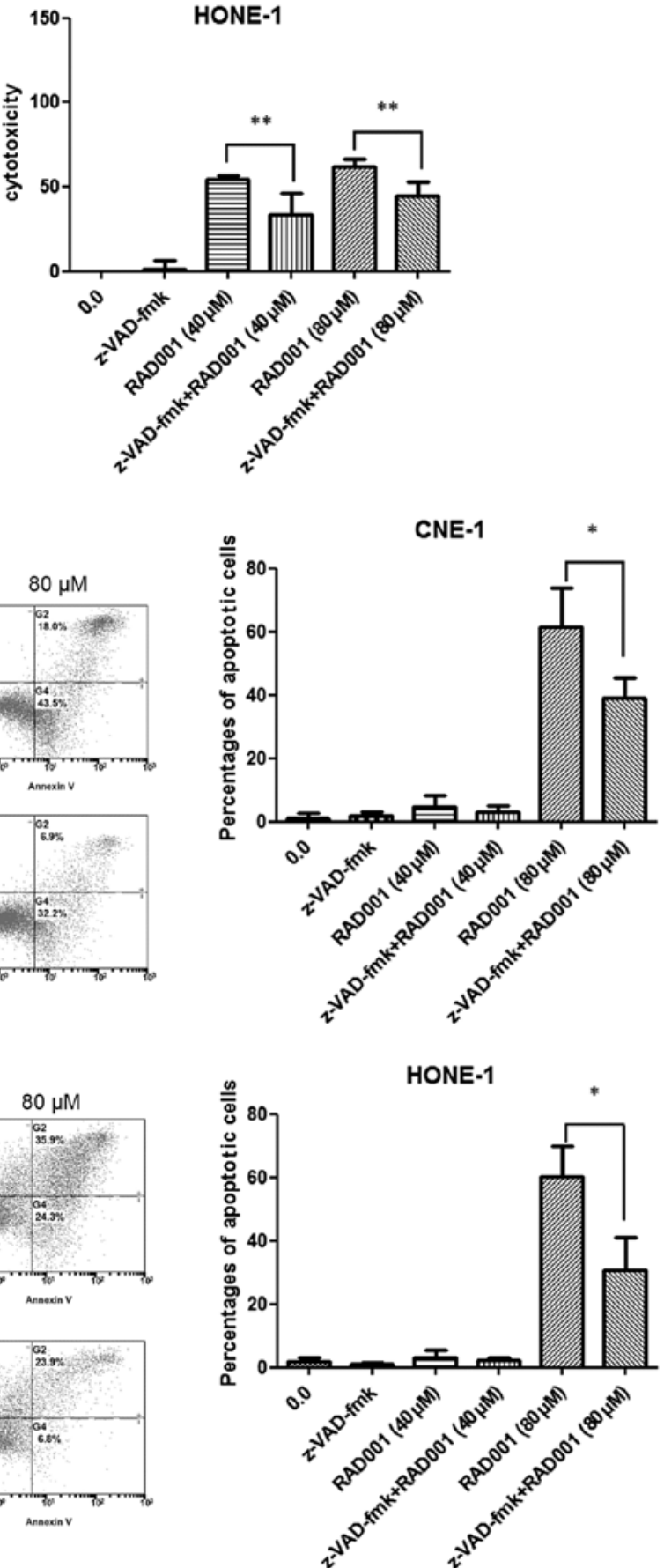

Figure 5. Effect of the combined RAD001 and z-VAD-fmk treatment on the growth and apoptosis of CNE-1 and HONE-1 cells. (A) Cells were exposed to RAD001 alone or in combination with z-VAD-fmk for $24 \mathrm{~h}$. The LDH assay was used to detect cytotoxicity. (B) Cells were exposed to RAD001 alone or in combination with z-VAD-fmk for $24 \mathrm{~h}$ and then stained using an Annexin V-FITC/PI apoptosis detection kit. Data points represent the means \pm SDs from triplicate experiments $\left({ }^{*} \mathrm{P}<0.05,{ }^{* *} \mathrm{P}<0.01\right)$.

cell control group. In regards to the CNE-1 cells, treatment with 40 or $80 \mu \mathrm{M}$ RAD001 resulted in Annexin V-FITC-positive staining rates of $4.7 \pm 3.6$ and $61.5 \pm 12.5 \%$ at $24 \mathrm{~h}$. When 40 or $80 \mu \mathrm{M}$ RAD001 was combined with $20 \mu \mathrm{M}$ z-VAD-fmk, the Annexin V-FITC-positive staining rates were reduced to $2.9 \pm 2.0 \%(\mathrm{P}>0.05)$ and $39.1 \pm 6.5 \%(\mathrm{P}<0.05)$, respectively. For HONE-1 cells, RAD001 of 40 or $80 \mu \mathrm{M}$ resulted in Annexin V-FITC-positive staining rates of 3.2 \pm 2.1 and $60.2 \pm 9.6 \%$ when compared to the rates in the control group $(1.7 \pm 1.4 \%)$ at $24 \mathrm{~h}$. When 40 or $80 \mu \mathrm{M}$ RAD001 was combined with z-VAD-fmk, the Annexin V-FITC-positive staining rates were reduced to $2.3 \pm 0.6 \%(\mathrm{P}>0.05)$ and $30.7 \pm 10.3 \%(\mathrm{P}<0.05)$, respectively (Fig. 5B).

\section{Discussion}

Nasopharyngeal cancer was invariably lethal prior to the advent of radiation. With improved knowledge and technology, locoregional control of this disease exceeds $90 \%$. However, further reduction of distant failure and major late toxicities remain as challenges, and the development of targeted therapy without cytotoxicity is urgently needed. There is a 
paucity of data concerning the preclinical activity of RAD001 in NPC. In the present study, we investigated the antitumor effect of RAD001 in a time- and dose-dependent manner in CNE-1 and HONE-1 cell lines. RAD001 induced a significant increase in growth inhibition in the two cell lines when used in combination with the autophagy inhibitor 3-MA; however, the percentages of apoptotic cells decreased when RAD001 was combined with the caspase inhibitor z-VAD-fmk.

Consistent with a previous report (22), the main mechanism of RAD001 in our study was the induction of apoptosis rather than autophagy. Moreover, RAD001 had only a modest effect on the cell cycle (data not shown), which is supported by both Beuvink et al (23) and Mabuchi et al (16). According to a recent report (24), RAD001 was found to increase both the cellular apoptotic rate and $\mathrm{S}$ phase cell cycle arrest. However, Zhu et al (25) reported that RAD001 induced $G_{1}$ phase arrest and increased the number of cells undergoing early apoptosis in breast cancer stem cells. Zhang et al (26) treated stem cells from primary breast cancer cells and breast cancer cell lines and observed that the combination treatment of RAD001 with docetaxel inhibited the growth of stem cells both in vitro and in vivo by inhibiting cell proliferation and inducing apoptosis and $\mathrm{G}_{2} / \mathrm{M}$ phase arrest. Others researchers described the molecular mechanism of RAD001 as inducing $\mathrm{G}_{1}$ cell cycle arrest in gastric cancer (27), mantle cell lymphoma (28), diffuse large B-cell lymphoma (29), esophageal cancer (30) and breast cancer (31). Still others have reported alternate mechanisms of action, including the induction of autophagy in prostate cancer (32), hepatocellular carcinoma (33) and acute lymphoblastic leukemia (34).

Rosich et al (35) demonstrated that the selective triple knockdown of the autophagy genes ATG7, ATG5 and ATG3 and pretreatment with the autophagy inhibitor hydroxychloroquine effectively overcame RAD001 resistance in a mantle cell lymphoma cell line, leading to the activation of the mitochondrial apoptotic pathway. In this study, cells displayed high levels of autophagy when RAD001 was used alone. We then combined RAD001 with autophagy inhibitor 3-MA to determine whether the response changed. We determined that the growth inhibition was enhanced, which is consistent with the study by Rosich et al. Because this growth inhibition was represented by additional cellular apoptosis, we evaluated whether caspase-3 inhibition in combination with RAD001 impaired its effect. Using an LDH assay and flow cytometry, we determined that the growth inhibitory effect was markedly reduced when RAD001 was used in combination with a caspase-3 inhibitor in both CNE-1 and HONE-1 cells.

Numerous reports suggest that autophagy is a survival mechanism protecting cells from cell death due to DNA damage. Other studies indicate that autophagy may be the mechanism of cell death during tumor treatment or that autophagy may be involved in the induction of apoptosis. Currently, both rapamycin (an mTOR inhibitor) and chloroquine (an autophagosome-lysosome fusion step blocker) are being used in combination with chemotherapy in clinical trials for different cancer types. Whether autophagy is an apoptosispromoting mechanism per se or whether it acts as a protective mechanism that reduces tumor cell death upon treatment is still a controversial and complicated issue that remains to be determined (36).
mTOR possesses both pro-apoptotic and anti-apoptotic effects. On one hand, mTOR is capable of translocating into the nucleus resulting in the phosphorylation and activation of p53. This in turn results in the transcription of the pro-apoptotic proteins BAX and others (37). On the other hand, activated S6K is capable of binding to mitochondrial membranes and phosphorylating BAD (38), which then becomes inactive and is unable to promote apoptosis. In the present study, we combined either an autophagy inhibitor or an apoptosis inhibitor with the mTOR inhibitor RAD001 and observed more cell death when autophagy was inhibited. This result suggests that mTOR possesses mainly anti-apoptotic effects in CNE-1 and HONE-1 cell lines. RAD001 combined with an autophagy inhibitor aggravated mTOR inhibition and thus enhanced the induction of apoptosis.

In conclusion, our results are the first to suggest that the inhibition of mTOR by RAD001 may result in a potential therapeutic benefit for NPC. The predominant mechanism involved was the induction of cellular apoptosis rather than cell cycle arrest or autophagy. The combination of RAD001 and the autophagy inhibitor 3-MA resulted in enhanced tumor inhibition by promoting tumor cell cytotoxicity. Therefore, our present observations may provide additional evidence to the growing amount of research that indicates the effectiveness of mTOR inhibition for treating cancer as well as a strong rationale for the clinical evaluation of RAD001 combined with autophagy inhibitors for the management of nasopharyngeal malignancies. Further experiments will need to be performed to verify our conclusion in vivo. Tumor samples will be collected and autophagy- and apoptosis-related proteins will be examined to confirm our conclusions.

\section{Acknowledgements}

This study was supported by the National Eleventh Five Technology Major Project (grant no. 2008ZX09312-002) and the National Natural Science Foundation of China (Young Scientist Project \#81201716)

\section{References}

1. Lee AW, Lin JC and Ng WT: Current management of nasopharyngeal cancer. Semin Radiat Oncol 22: 233-244, 2012.

2. Ma BB, Hui EP and Chan AT: Systemic approach to improving treatment outcome in nasopharyngeal carcinoma: current and future directions. Cancer Sci 99: 1311-1318, 2008.

3. Qian W, Liu J, Jin J, Ni W and Xu W: Arsenic trioxide induces not only apoptosis but also autophagic cell death in leukemia cell lines via up-regulation of Beclin-1. Leuk Res 31: 329-339, 2007.

4. Basciani S, Vona R, Matarrese P, Ascione B, Mariani S, Cauda R, Gnessi L, Malorni W, Straface E and Lucia MB: Imatinib interferes with survival of multi drug resistant Kaposi's sarcoma cells. FEBS Lett 581: 5897-5903, 2007.

5. Yang W, Monroe J, Zhang Y, George D, Bremer E and Li H: Proteasome inhibition induces both pro- and anti-cell death pathways in prostate cancer cells. Cancer Lett 243: 217-227, 2006.

6 . Hay N and Sonenberg N: Upstream and downstream of mTOR. Genes Dev 18: 1926-1945, 2004.

7. Huang S and Houghton PJ: Targeting mTOR signaling for cancer therapy. Curr Opin Pharmacol 3: 371-377, 2003.

8. Gomez-Pinillos A and Ferrari AC: mTOR signaling pathway and mTOR inhibitors in cancer therapy. Hematol Oncol Clin North Am 26: 483-505, 2012.

9. Grzybowska-Izydorczyk O and Smolewski P: mTOR kinase inhibitors as a treatment strategy in hematological malignancies. Future Med Chem 4: 487-504, 2012. 
10. Zoncu R, Efeyan A and Sabatini DM: mTOR: from growth signal integration to cancer, diabetes and ageing. Nat Rev Mol Cell Biol 12: 21-35, 2011.

11. Wan $X$ and Helman LJ: The biology behind mTOR inhibition in sarcoma. Oncologist 12: 1007-1018, 2007.

12. Chan S: Targeting the mammalian target of rapamycin (mTOR): a new approach to treating cancer. Br J Cancer 91: 1420-1424, 2004

13. Vignot S, Faivre S, Aguirre D and Raymond E: mTOR targeted therapy of cancer with rapamycin derivatives. Ann Oncol 16: 525-537, 2005 .

14. Lin CI, Whang EE, Donner DB, Du J, Lorch J, He F, Jiang X, Price BD, Moore FD Jr and Ruan DT: Autophagy induction with RAD001 enhances chemosensitivity and radiosensitivity through Met inhibition in papillary thyroid cancer. Mol Cancer Res 8: 1217-1226, 2010

15. Molinolo AA, Marsh C, El Dinali M, Gangane N, Jennison K, Hewitt S, Patel V, Seiwert TY and Gutkind JS: mTOR as a molecular target in HPV-associated oral and cervical squamous carcinomas. Clin Cancer Res 18: 2558-2568, 2012.

16. Mabuchi S, Altomare DA, Cheung M, Zhang L, Poulikakos PI, Hensley HH, Schilder RJ, Ozols RF and Testa JR: RAD001 inhibits human ovarian cancer cell proliferation, enhances cisplatin-induced apoptosis, and prolongs survival in an ovarian cancer model. Clin Cancer Res 13: 4261-4270, 2007.

17. Götze KS, Hoffmann D, Schätzl HM, Peschel C, Fend F and Decker T: Fatal Epstein-Barr virus-associated lymphoproliferative disorder following treatment with a novel mTOR inhibitor for relapsed chronic lymphocytic leukemia cells Haematologica 92: 1282-1283, 2007.

18. Ghayad SE, Bieche I, Vendrell JA, Keime C, Lidereau R, Dumontet $\mathrm{C}$ and Cohen PA: mTOR inhibition reverses acquired endocrine therapy resistance of breast cancer cells at the cell proliferation and gene-expression levels. Cancer Sci 99: 1992-2003, 2008.

19. Zitzmann K, De Toni EN, Brand S, Göke B, Meinecke J, Spöttl G, Meyer HH and Auemhammer CJ: The novel mTOR inhibitor RAD001 (everolimus) induces antiproliferative effects in human pancreatic neuroendocrine tumor cells. Neuroendocrinology 85 54-60, 2007.

20. Patel V, Marsh CA, Dorsam RT, Mikelis CM, Masedunskas A, Amornphimoltham P, Nathan CA, Singh B, Weigert R, Molinolo AA and Gutkind JS: Decreased lymphangiogenesis and lymph node metastasis by mTOR inhibition in head and neck cancer. Cancer Res 71: 7103-7112, 2011.

21. Yip WK, Leong VC, Abdullah MA, Yusoff S and Seow HF: Overexpression of phospho-Akt correlates with phosphorylation of EGF receptors, FKHR and BAD in nasopharyngeal carcinoma. Oncol Rep 19: 319-328, 2008.

22. Ma BB, Lui VW, Hui EP, Lau CP, Ho K, Ng MH, Cheng SH, Tsao SW and Chan AT: The activity of mTOR inhibitor RAD001 (everolimus) in nasopharyngeal carcinoma and cisplatin-resistant cell lines. Invest New Drugs 28: 413-420, 2010.

23. Beuvink I, Boulay A, Fumagalli S, Zilbermann F, Ruetz S, O'Reilly T, Natt F, Hall J, Lane HA and Thomas G: The mTOR inhibitor RAD001 sensitizes tumor cells to DNA-damaged induced apoptosis through inhibition of p21 translation. Cell 120: 747-759, 2005.

24. Pinto-Leite R, Arantes-Rodrigues R, Palmeira C, Gaivão I, Cardoso ML, Colaço A, Santos L and Oliveira P: Everolimus enhances gemcitabine-induced cytotoxicity in bladder-cancer cell lines. J Toxicol Environ Health A 75: 788-799, 2012.
25. Zhu Y, Zhang X, Liu Y, Zhang S, Liu J, Ma Y and Zhang J: Antitumor effect of the mTOR inhibitor everolimus in combination with trastuzumab on human breast cancer stem cells in vitro and in vivo. Tumour Biol 33: 1349-1362, 2012.

26. Zhang X, Zhang S, Liu Y, Liu J, Ma Y, Zhu Y and Zhang J: Effects of the combination of RAD001 and docetaxel on breast cancer stem cells. Eur J Cancer 48: 1581-1592, 2012.

27. Lee KH, Hur HS, Im SA, Lee J, Kim HP, Yoon YK, Han SW, Song SH, Oh DY, Kim TY and Bang YJ: RAD001 shows activity against gastric cancer cells and overcomes 5-FU resistance by downregulating thymidylate synthase. Cancer Lett 299: 22-28, 2010.

28. Haritunians T, Mori A, O'Kelly J, Luong QT, Giles FJ and Koeffler HP: Antiproliferative activity of RAD001 (everolimus) as a single agent and combined with other agents in mantle cell lymphoma. Leukemia 21: 333-339, 2007.

29. Wanner K, Hipp S, Oelsner M, Ringshausen I, Bogner C, Peschel $\mathrm{C}$ and Decker T: Mammalian target of rapamycin inhibition induces cell cycle arrest in diffuse large B cell lymphoma (DLBCL) cells and sensitises DLBCL cells to rituximab. Br J Haematol 134: 475-484, 2006.

30. Wang ZG, Fukazawa T, Nishikawa T, Watanabe N, Sakurama K, Motoki T, Hatakeyama S, Omori O, Ohara T, Tanabe S, Fujiwara Y, Takaoka M, Shirakawa Y, Yamatsuji T, Tanaka N and Naomoto Y: RAD001 offers a therapeutic intervention through inhibition of mTOR as a potential strategy for esophageal cancer. Oncol Rep 23: 1167-1172, 2010.

31. Liu H, Scholz C, Zang C, Schefe JH, Habbel P, Regierer AC, Schulz CO, Possinger K and Eucker J: Metformin and the mTOR inhibitor everolimus (RAD001) sensitize breast cancer cells to the cytotoxic effect of chemotherapeutic drugs in vitro. Anticancer Res 32: 1627-1637, 2012.

32. Cao C, Subhawong T, Albert JM, Kim KW, Geng L, Sekhar KR, Gi YJ and Lu B: Inhibition of mammalian target of rapamycin or apoptotic pathway induces autophagy and radiosensitizes PTEN null prostate cancer cells. Cancer Res 66: 10040-10047, 2006.

33. Altmeyer A, Josset E, Denis JM, Gueulette J, Slabbert J, Mutter D, Noël G and Bischoff P: The mTOR inhibitor RAD001 augments radiation-induced growth inhibition in a hepatocellular carcinoma cell line by increasing autophagy. Int J Oncol 41: 1381-1386, 2012.

34. Crazzolara R, Bradstock KF and Bendall LJ: RAD001 (everolimus) induces autophagy in acute lymphoblastic leukemia. Autophagy 5: 727-728, 2009.

35. Rosich L, Xargay-Torrent S, López-Guerra M, Campo E, Colomer D and Roué G: Counteracting autophagy overcomes resistance to everolimus in mantle cell lymphoma. Clin Cancer Res 18: 5278-5289, 2012.

36. Maycotte $\mathrm{P}$ and Thorburn A: Autophagy and cancer therapy. Cancer Biol Ther 11: 127-137, 2011.

37. Castedo M, Roumier T, Blanco J, Ferri KF, Barretina J, Tintignac LA, Andreau K, Perfettini JL, Amendola A, Nardacci R, Leduc P, Ingber DE, Druillennec S, Roques B, Leibovitch SA, Vilella-Bach M, Chen J, Este JA, Modjtahedi N, Piacentini M and Kroemer G: Sequential involvement of Cdk1, mTOR and p53 in apoptosis induced by the HIV-1 envelope. EMBO J 21: 4070-4080, 2002.

38. Li B, Desai SA, MacCorkle-Chosnek RA, Fan L and Spencer DM: A novel conditional Akt 'survival switch' reversibly protects cells from apoptosis. Gene Ther 9: 233-244, 2002. 